\title{
In vitro fertilization and embryo transfer alter human placental function through trophoblasts in early pregnancy
}

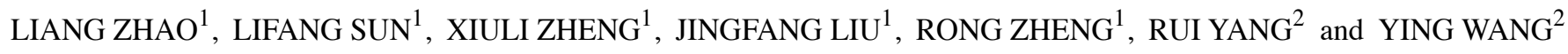 \\ ${ }^{1}$ Department of Obstetrics and Gynecology, Beijing Jishuitan Hospital, Beijing 100035; \\ ${ }^{2}$ Department of Obstetrics and Gynecology, Peking University Third Hospital, Beijing 100191, P.R. China
}

Received March 16, 2019; Accepted December 10, 2019

DOI: $10.3892 / \mathrm{mmr} .2020 .10971$

\begin{abstract}
The mechanism underlying the potential risk associated with in vitro fertilization and embryo transfer (IVF-ET) has been previously investigated but remains to be fully elucidated. As the placenta is a critical organ that sustains and protects the fetus, this is an important area of research. The aim of the present study was to determine the difference in trophoblast cell function in the first trimester between naturally conceived pregnancies and pregnancies achieved via IVF-ET therapy. A total of 20 placental villi in first trimester samples were obtained through fetal bud aspiration from patients undergoing IVF-ET due to oviductal factors between January 2016 and August 2018. In addition, a further 20 placental villi were obtained from those who naturally conceived and had normal pregnancies but were undergoing artificial abortion; these patients were recruited as the controls. Reverse transcription-quantitative (RT-q)PCR and semi-quantitative immunohistochemical methods were used to detect the mRNA and protein expression of $\alpha$-fetoprotein (AFP), vascular endothelial growth factor (VEGF), transferrin (TF), tubulin $\beta 1$ class VI (TUBB1), metallothionein 1G (MT1G), BCL2, glial cells missing transcription factor 1 (GCM1), epidermal growth factor (EGF) receptor (EGFR), PTEN and leukocyte associated immunoglobulin like receptor 2 (LAIR2) in villi from both groups. Differentially expressed genes were analyzed using Search Tool for the Retrieval of Interacting Genes, and Kyoto Encyclopedia of Genes and Genomes (KEGG) pathway analysis was conducted. The RT-qPCR data revealed that the mRNA expression levels of AFP, VEGF and TF were significantly higher in the IVF-ET group than in the control group $(\mathrm{P}<0.05)$, and those of TUBB1, MT1G, BCL2, GCM1, EGFR,
\end{abstract}

Correspondence to: Professor Lifang Sun or Dr Liang Zhao, Department of Obstetrics and Gynecology, Beijing Jishuitan Hospital, 31 Xinjiekou East Street, Xicheng, Beijing 100035, P.R. China

E-mail: lifangsun1966@aliyun.com

E-mail: zhaol1972@aliyun.com

Key words: in vitro fertilization and embryo transfer, natural pregnancy, placental function, trophoblast, disease
PTEN and LAIR2 were significantly lower $(\mathrm{P}<0.05)$. These gene products were expressed in the placental villus tissues, either in the cytoplasm, or in the membrane of syncytiotrophoblast and cytotrophoblast cells. The immunohistochemistry results were in line with those observed using RT-qPCR. KEGG pathway analysis indicated that the trophoblast cell function of the IVF-ET group in the first trimester was different from naturally conceived pregnancies with regard to proliferation, invasion, apoptosis and vascular development. The IVF-ET process may trigger adaptive placental responses, and these compensatory mechanisms could be a risk for certain diseases later in life.

\section{Introduction}

There is currently growing interest in the potential risks associated with assisted reproductive technology (ART). After adjusting for several confounding factors, the risk of numerous adverse outcomes during the perinatal period, including miscarriage, premature birth, low birth weight, intra-uterine growth retardation and gestational hypertension, are higher in in vitro fertilization and embryo transfer (IVF-ET) cohorts than for spontaneous pregnancies (1-3). Over the last few years, the early stages of mammalian embryonic development have been shown to be very sensitive to the microenvironment, with long term effects on fetal, postnatal and adult health (4-6). The developmental origins of health and disease hypothesis, based on the evidence that prenatal exposure to modified environmental conditions affects postnatal growth, metabolism and disease susceptibility in adulthood, has been altered to include the preimplantation stages of development $(7,8)$. The basal risk associated with pregnancy in a population varies greatly with time and place, and professionals need to be proactive in order to prevent them.

There are an increasing number of well-designed studies that have reported that placental tissues are more sensitive to preimplantation epigenetic disturbances in imprinted genes than embryonic tissues (9-11). This may lead to abnormal placental development and function, with possibly adverse consequences for the developing fetus. In regard to this observation, previous studies have proposed two scenarios to explain why the defects were apparently restricted to the trophectoderm lineage $(12,13)$. On the one hand, trophectoderm cells, in contact with the culture medium, are more 
severely affected by in vitro culture, which is responsible for a loss of imprinting in the mid-gestation placenta (14). On the other hand, they are also the first lineage to differentiate in the embryo as trophectoderm stem cells, from which the different cell lines of the future placenta will originate $(15,16)$. In addition to culture media composition, which differs from the in vivo natural environment despite careful manipulation, in vitro production of trophectoderm cells is associated with several environmental stressors, such as oxygen tension, $\mathrm{pH}$ and temperature variations during manipulation, light exposure and shear stress linked to repeated pipetting, which may affect placental development and function $(17,18)$.

A growing body of evidence in the literature supports the hypothesis that a number of adverse pregnancy outcomes observed after IVF-ET originate from suboptimal placenta function caused by abnormal trophoblastic invasion due to a disturbed dialogue during the early phases of placentation $(19,20)$. Fetal-maternal interactions involve a finely balanced synergistic cross-talk of inflammatory and immune modulating factors to allow for maternal immune adaption and tolerance of the semiallogeneic fetus (21). Thus, it is well acknowledged that the placenta functions as an immune-modulating organ that regulates the immune responses of trophoblast cells present both at the implantation site and systemically (22). Increasing evidence indicates that metabolic and proinflammatory conditions affect trophoblastic invasion, as well as placental function and growth in the first trimester of pregnancy long before any phenotypic changes become clinically apparent (23). Furthermore, it is increasingly recognized that trophoblast invasion and placental function early in gestation directly affects fetal development by responding to the environment (24). Therefore, it is important to understand the changes in trophoblastic invasion in placentas subjected to IVF-ET processes; however, little is known concerning this.

In the present study, it was hypothesized that altered gene and protein expression occurs in placental tissues during the first trimester after IVF-ET compared with placental tissues from spontaneous pregnancies. Therefore, the present study analyzed candidate factors related to trophoblast invasion and placental function, to investigate and determine the potential effects of IVF-ET treatment on gene expression in the placenta during the early stages of pregnancy. The aim of the present study was to explore the possible causal relationship between IVF-ET procedures and the higher frequency of adverse pregnancy outcomes. Furthermore, improving the understanding of the placental mechanisms triggered by IVF-ET may be of future value to improve the safety of IVF-ET protocols.

\section{Materials and methods}

Ethical statement. The research program was approved by the Ethical Committee of Beijing Jishuitan Hospital (permission no. 201703-11) and Peking University Third Hospital (permission no. 2014-075), and all participants provided written informed consent.

Patients. Between January 2016 and August 2018, twin to singleton fetal reduction was performed in a total of 20 cases at a mean of $49 \pm 6$ days of pregnancy after IVF-ET treatment (age range, 23-35 years; mean age, 30.8 years) at Beijing Jishuitan
Hospital and Peking University Third Hospital. The clinical application of IVF-ET was licensed by the Ministry of Health of The People's Republic of China. The control group included 20 cases of unwanted twin pregnancies in the same period (age range, 24-30 years; mean age, 28.9 years). Selection criteria: Patients underwent IVF-ET due to oviductal obstruction; the quality of each male sperm was normal; reasons for fetal reduction in the 20 cases were the patients' demand. Women who had abnormal menstruation, smoked, drunk alcohol or used any steroid hormone drugs in the previous 3 months were excluded. Clinical data were collected by the Department of Obstetrics and Gynecology at Beijing Jishuitan Hospital and Peking University Third Hospital, and organized in a database. Each of the 20 placental specimens from the IVF-ET group was matched to each of the 20 controls by parity, maternal age and number of gestational weeks.

Sample collection. All of the fetal reductions were performed by the same senior physician through fetal bud aspiration under B ultrasound guidance. The present study selected 20 cases for villi suction at the same time. The tissues were collected 30-45 days after embryo transfer, which is equivalent to 45-50 days of pregnancy. The control group were diagnosed with early intrauterine pregnancy after bimanual examination, urine pregnancy tests and B ultrasound. All of the patients had regular menstruation and had not taken any steroid hormone drugs in the previous 3 months. The villi were obtained during the conventional artificial abortion operation in the control group. The villi samples were purified immediately from the specimens within $1 \mathrm{~h}$ under an inverted microscope. All samples were then floated in ice-cold PBS, and finally stored in liquid nitrogen until future total RNA extraction. Another part of the remaining specimen was immersed in $4 \%$ formalin for $24 \mathrm{~h}$ at $4^{\circ} \mathrm{C}$, and then taken out and rinsed with running water for $30 \mathrm{~min}$. The villi then underwent routine dehydration, wax dipping, embedding and slicing.

$R N A$ preparation and reverse transcription-quantitative $(R T-q) P C R$. Tissue homogenization and RNA extraction were performed at CapitalBio Corporation. Homogenization of the tissue and isolation of the total RNA were performed using TRIzol $^{\circledR}$ (Invitrogen; Thermo Fisher Scientific, Inc.) according to the standard method. The RNA, extracted with ribosomal $28 \mathrm{~S}$ and 18S RNA with a ratio of intensities of 1.5-1.8:1, was used for RT-qPCR analysis. Complementary DNA (cDNA) was generated using a PrimeScript II 1st Strand cDNA synthesis kit (Takara Biotechnology Co., Ltd.) using random or oligo(dT) primers for $15 \mathrm{~min}$ at $37^{\circ} \mathrm{C}, 5 \mathrm{sec}$ at $85^{\circ} \mathrm{C}$. qPCR was performed using a SYBR-Green PCR Master mix (Takara Biotechnology Co., Ltd.). Specific forward and reverse primer pairs were designed for each gene and are listed in Table I. Amplification was performed using the following thermocycling conditions: $94^{\circ} \mathrm{C}$ for $5 \mathrm{~min} ; 95^{\circ} \mathrm{C}$ for $30 \mathrm{sec}, 62^{\circ} \mathrm{C}$ for $30 \mathrm{sec}$ and $72^{\circ} \mathrm{C}$ for $30 \mathrm{sec}$ ( 35 cycles); and a final extension at $72^{\circ} \mathrm{C}$ for $10 \mathrm{~min}$. To minimize variation in the $\mathrm{RT}$ reaction, all the RNA samples from a single experimental setup were reverse transcribed simultaneously (25). For the in vitro experiments, the relative expression of mRNA was calculated using the comparative quantitative cycle $\left(2^{-\Delta \Delta C q}\right)$ method $(26,27)$ and normalized to the internal control human gene GAPDH (28). 
Table I. Primer sequences used for reverse transcription-quantitative PCR amplification and the conditions.

\begin{tabular}{|c|c|c|c|c|}
\hline Gene & Primer sequence $\left(5^{\prime}-3^{\prime}\right)$ & Annealing temperature $\left({ }^{\circ} \mathrm{C}\right)$ & Cycles & Product size (bp) \\
\hline \multirow[t]{2}{*}{ AFP } & F: TCCAGCCAAAGTGAAGAGGG & 59 & 35 & 471 \\
\hline & R: CAAGCTGCTITCTCTTAATTC & & & \\
\hline \multirow[t]{2}{*}{ GCM1 } & F: GGCCGATCCAGCTATATCAA & 58 & 42 & 254 \\
\hline & R: CTGGGGTGCACATAGTGAAA & & & \\
\hline \multirow[t]{2}{*}{ LAIR2 } & F: GCCATGTCTCCACACCTC & 60 & 45 & 428 \\
\hline & R: GAAGTTCACAAGACGGGAGG & & & \\
\hline \multirow[t]{2}{*}{ PTEN } & F: CGACGGGAAGACAAGACAGTAG & 60 & 42 & 330 \\
\hline & R: GCTAGCCTCTGGATTTGACG & & & \\
\hline \multirow[t]{2}{*}{ BCL2 } & F: CAGATGGCAAATGACCAGCAGA & 58 & 38 & 375 \\
\hline & R: TGGCAGGATAGCAGCACAGGAT & & & \\
\hline \multirow[t]{2}{*}{$\mathrm{TF}$} & F: GCAATGGGCAGATAGAGTGT & 60 & 40 & 256 \\
\hline & R: GTGTTCTTTCGTTCGTGTT & & & \\
\hline \multirow[t]{2}{*}{ MT1G } & F: TCGCTTGAGATCTCCAGCCTTAC & 59 & 42 & 280 \\
\hline & R: ACATCTGGGAGAAGAGCTGTCC & & & \\
\hline \multirow[t]{2}{*}{ EGFR } & F: GGACTCTGGATCCCAGAAGGTG & 58 & 45 & 332 \\
\hline & R: GCTGGCCATCACGTAGGCTT & & & \\
\hline \multirow[t]{2}{*}{ VEGF } & F: ATGAACTTTCTCTGCTGTCTGG & 57 & 35 & 354 \\
\hline & R: TCACCGCCTCGGCTTGTCACA & & & \\
\hline \multirow[t]{2}{*}{ TUBB1 } & F: TTCCAGCTGACCCACTCTCT & 60 & 42 & 434 \\
\hline & R: ACAGGGCCTCGTI'ATCAATG & & & \\
\hline \multirow[t]{2}{*}{ GAPDH } & F: GGTGCTGAGTATGTCGTGGAGT & 58 & 42 & 212 \\
\hline & R: CAGTCTTCTGAGTGGCAGGAT & & & \\
\hline
\end{tabular}

F, forward; R, reverse; AFP, $\alpha$-fetoprotein; VEGF, vascular endothelial growth factor; TF, transferrin; TUBB1, tubulin $\beta 1$ class VI; MT1G, metallothionein 1G; GCM1, glial cells missing transcription factor 1; EGFR, epidermal growth factor receptor; LAIR2, leukocyte associated immunoglobulin like receptor 2 .

Immunohistochemistry (IHC). Placental tissues were embedded in paraffin and sectioned for IHC. After drying in an oven at $60^{\circ} \mathrm{C}$ for $2 \mathrm{~h}$, tissue sections $(4 \mu \mathrm{m})$ were deparaffinized in xylene and rehydrated through a descending alcohol series. Endogenous peroxides were quenched by immersing the tissue sections in $3 \%$ hydrogen peroxide in methanol for $10 \mathrm{~min}$ at room temperature. After heat induction in citric acid for 15 min and blocking with $1 \%$ bovine serum albumin (Sigma-Aldrich; Merck KGaA) for $20 \mathrm{~min}$ at $4^{\circ} \mathrm{C}$, the slides were incubated at $4^{\circ} \mathrm{C}$ overnight with polyclonal antibodies. The following primary antibodies (1:50 dilution unless otherwise specified) were used: $\alpha$-fetoprotein (AFP; cat. no. ZA-0612; Beijing Zhongshan Golden Bridge Biotechnology Co., Ltd.; OriGene Technologies, Inc.), vascular endothelial growth factor (VEGF; cat. no. ZM-0265; Beijing Zhongshan Golden Bridge Biotechnology Co., Ltd.; OriGene Technologies, Inc.), transferrin (TF; cat. no. TA500848; Beijing Zhongshan Golden Bridge Biotechnology Co., Ltd.; OriGene Technologies, Inc.), tubulin $\beta 1$ class VI (TUBB1; cat. no. TA506805; Beijing Zhongshan Golden Bridge Biotechnology Co., Ltd.; OriGene Technologies, Inc.), metallothionein 1G (MT1G cat. no. LS-B13009; LifeSpan BioSciences), BCL2 (cat. no. ZM-0010; Beijing Zhongshan Golden Bridge Biotechnology Co., Ltd.; OriGene Technologies, Inc.), glial cells missing transcription factor 1 (GCM1; 1:100 dilution; cat. no. ab187860; Abcam), epidermal growth factor receptor
(EGFR; cat. no. ZM-0093; Beijing Zhongshan Golden Bridge Biotechnology Co., Ltd.; OriGene Technologies, Inc.), PTEN (cat. no. ZA-0635; Beijing Zhongshan Golden Bridge Biotechnology Co., Ltd.; OriGene Technologies, Inc.) and leukocyte associated immunoglobulin like receptor 2 (LAIR2; 1:100 dilution; cat. no. ab183145; Abcam). After washing with PBS, the sections were subsequently incubated with SignalStain ${ }^{\circledR}$ Boost IHC detection reagent (horseradish peroxidase, rabbit; cat. no. 8114P; Cell Signaling Technology, Inc.) for $1 \mathrm{~h}$ at room temperature. Negative controls received PBS instead of primary antibodies. Staining was completed by incubation with diaminobenzidine tetrahydrochloride for $4 \mathrm{~min}$ at room temperature, and tissues were counterstained with hematoxylin for $5 \mathrm{~min}$ at room temperature. Immunohistochemical staining of samples and negative controls was simultaneously executed.

Assessment of the immunohistochemical staining results. The immunohistochemical staining of the villi in the slices was observed using optical microscopy (Eclipse 80i; Nikon Corporation). The positive reaction products were brown-yellow granules. Image-Pro Plus analysis software version 6.0 (Media Cybernetics, Inc.) was used on the immunohistochemical data for semi-quantitative analysis of the staining intensity. Images were viewed at magnification, $x 400$ using the double-blind method and ordinary illumination, and 5 areas from each 
Table II. Characteristics of the patients in the two groups.

\begin{tabular}{|c|c|c|c|c|}
\hline Characteristic & IVF-ET group $(n=20)$ & Control group $(n=20)$ & T-statistic & P-value \\
\hline Mean age (years) & $30.66 \pm 3.76$ & $28.86 \pm 3.45$ & 0.823 & 0.425 \\
\hline Gestational age (day) & $49.44 \pm 3.14$ & $49.35 \pm 3.23$ & 0.637 & 0.529 \\
\hline Gravidity & $1.10 \pm 1.21$ & $2.21 \pm 0.89$ & 0.858 & 0.437 \\
\hline BMI $\left(\mathrm{kg} / \mathrm{m}^{2}\right)$ & $23.33 \pm 3.17$ & $22.99 \pm 2.35$ & 1.311 & 0.263 \\
\hline
\end{tabular}

IVF-ET, in vitro fertilization and embryo transfer.

slice were randomly selected on the high-resolution monitor. The mean optical density (MOD) of positive expression was measured in each area, and the mean was calculated to obtain a MOD that was representative of the slice. A total of 5 slices from each sample were assessed, and the mean of each group was calculated.

Gene expression data analysis. The Kyoto Encyclopedia of Genes and Genomes (KEGG; http://www.kegg.jp/ or http://www.genome.jp/kegg/) (29) Orthology-Based Annotation System (KOBAS; version 2.0; http://kobas.cbi.pku.cn) was employed to identify enriched KEGG pathways based on an adjusted P-value. Search Tool for the Retrieval of Interacting Genes (STRING; version 11.0) software was used to draw the genetic interaction network (https://string-db.org/). The false discovery rate (FDR) was provided by KEGG.

Statistical analysis. SPSS software (version 21.0; IBM Corp.) was used for the collection, processing and statistical analysis of the data. The data were expressed as the mean \pm standard error. Statistical analysis was performed using independent samples t-tests for comparison of the means. $\mathrm{P}<0.05$ was considered to indicate a statistically significant difference.

\section{Results}

Characteristics of the patients. There were no statistical differences between the two groups of women in terms of age, gestational age and body mass index (Table II).

mRNA expression. Based on their biological processes mostly related to placental functions, 10 genes were selected and their mRNA expression was measured in the placenta using RT-qPCR. The results of RT-qPCR demonstrated that the placental mRNA expression levels of AFP, VEGF and TF were significantly increased in the IVF-ET group compared with the control group (Fig. 1). In addition, the placental mRNA expression of TUBB1, MT1G, BCL2, GCM1, EGFR, PTEN and LAIR2 was significantly decreased in the IVF-ET group compared with in the control as analyzed by RT-qPCR. Among the 10 tested genes, the present study observed a significant concordance with the results observed in IHC.

$I H C$. To verify the differentially expressed gene products in the human placenta, the present study localized protein expression via IHC. All selected proteins were located in either the cytoplasm or cytomembrane of syncytiotrophoblasts and cytotrophoblast cells in the placental villi tissues obtained from both the IVF-ET and control groups. The protein expression levels of AFP, VEGF and TF in the placental villi of the IVF-ET group were significantly higher than those in the control group (Fig. 2). The protein expression of TUBB1, MT1G, BCL2, GCM1, EGFR, PTEN and LAIR2 in the placental villi of the IVF-ET group was lower than those in the control group (Figs. 2 and 3). The products of AFP, VEGF and TF were expressed in both villous syncytiotrophoblasts and cytotrophoblast cells in the IVF-ET group, whereas there was only low expression in the villous syncytiotrophoblasts in the control group (Fig. 2). TUBB1 was observed in the cytoplasm and cytomembrane of villous cytotrophoblast cells and syncytiotrophoblasts in the IVF-ET group, whereas there was more diffuse TUBB1 staining in the control group (Fig. 2). MT1G was poorly expressed in villous cytotrophoblast cells and syncytiotrophoblasts in the IVF-ET group, and it was highly expressed in vascular endothelial cells and syncytiotrophoblasts in the control group (Fig. 2). BCL2 was widely distributed in the cytoplasm and cytomembrane of villous syncytiotrophoblasts and cytotrophoblast cells during early pregnancy. In the IVF-ET group, low expression of BCL2 was observed in both types of cells (Fig. 3). GCM1 was located in the plasma of the cytotrophoblast cells and syncytiotrophoblasts of early villi, and it was poorly expressed in all cell types unlike the other selected gene products (Fig. 3). EGFR was found in the plasma and cytomembrane of syncytiotrophoblasts and cytotrophoblast cells, and it was more strongly expressed on the surface of syncytiotrophoblasts in the control group compared with the IVF-ET group (Fig. 3). PTEN and LAIR2 were widely expressed in the cytoplasm and cytomembrane of villous syncytiotrophoblasts and cytotrophoblast cells in early pregnancy. In the IVF-ET group, lower expression of PTEN and LAIR2 was observed in both types of cells compared with the control group (Fig. 3).

Quantitative analysis of immunohistochemical images. After staining, photographs of 5 random fields for each placental villus were taken, and the MOD of the photographs was calculated (Table SI). The expression of AFP, VEGF and TF in the placental villi of the IVF-ET group was significantly higher than that observed in the control group $(\mathrm{P}<0.05$; Table $\mathrm{SI})$. However, TUBB1, MT1G, BCL2, GCM1, EGFR, PTEN and LAIR2 expression was significantly lower in the placental villi of the IVF-ET group when compared with the control group $(\mathrm{P}<0.05$; Fig. 4; Table SI). 

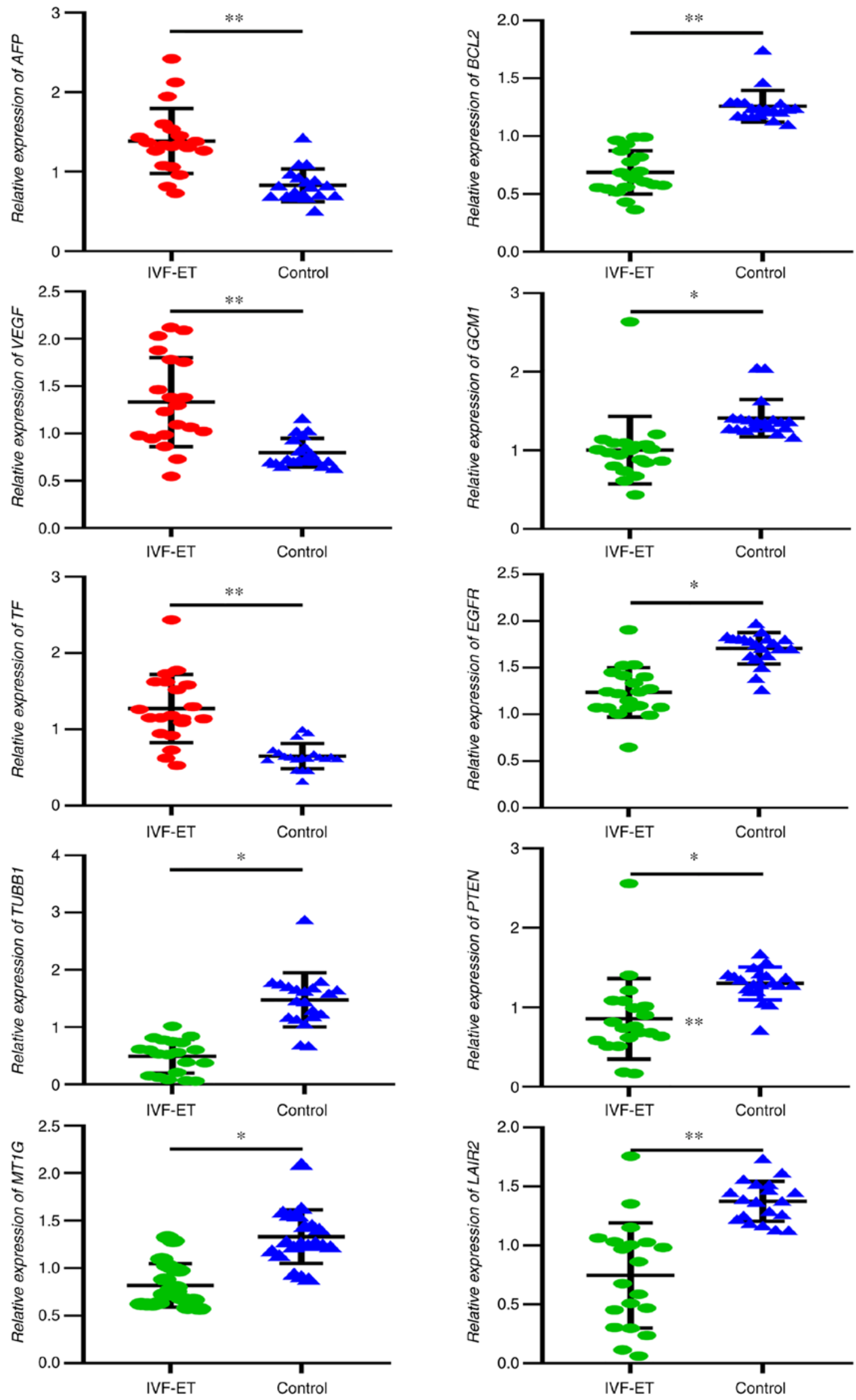

Figure 1. Results of reverse transcription-quantitative PCR analysis of selected genes from placentas derived from IVF-ET manipulation and natural pregnancies. ${ }^{*} \mathrm{P}<0.05,{ }^{* * *} \mathrm{P}<0.01$. IVF-ET, in vitro fertilization and embryo transfer; AFP, $\alpha$-fetoprotein; VEGF, vascular endothelial growth factor; TF, transferrin; TUBB1, tubulin $\beta 1$ class VI; MT1G, metallothionein 1G; GCM1, glial cells missing transcription factor 1; EGFR, epidermal growth factor receptor; LAIR2, leukocyte associated immunoglobulin like receptor 2. 


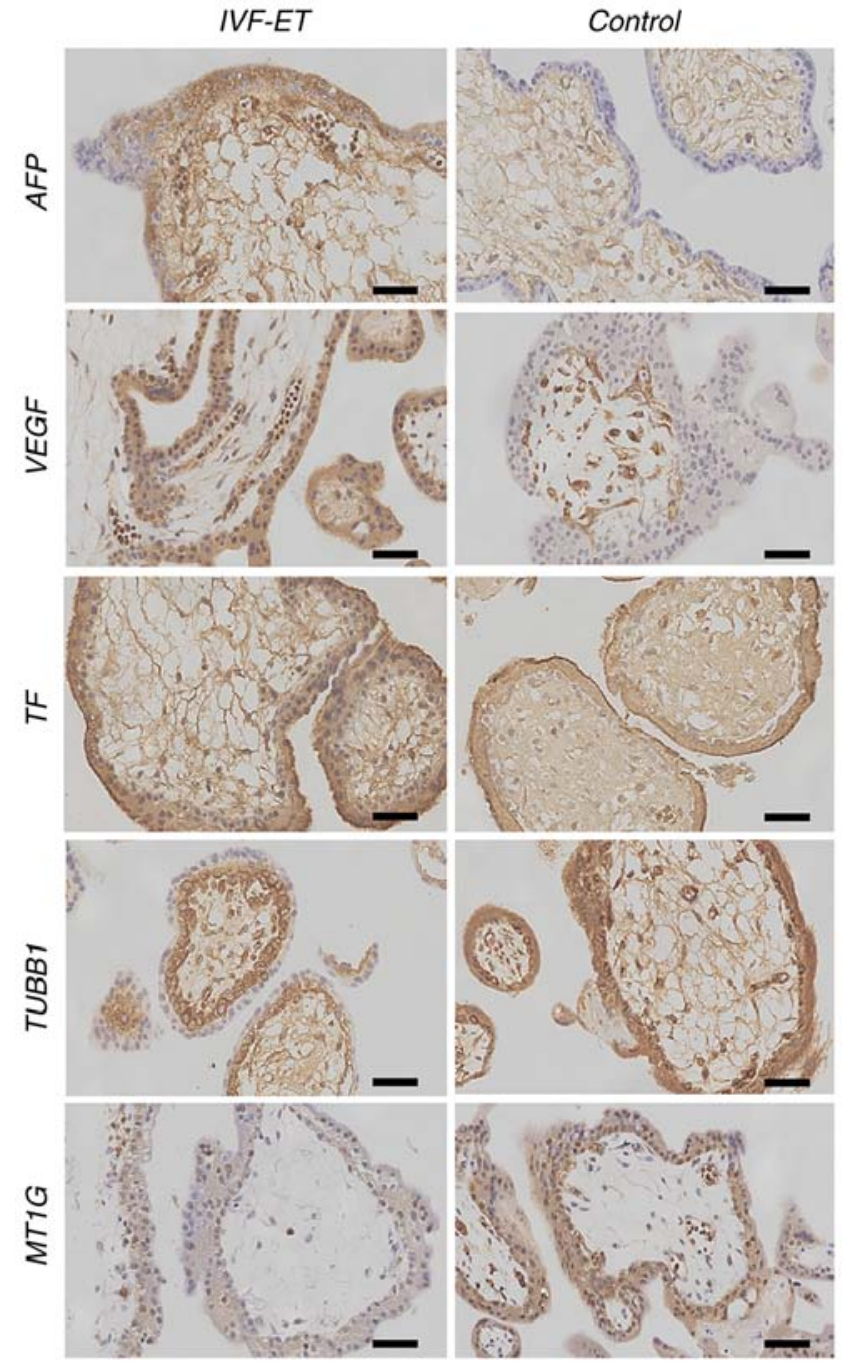

Figure 2. Immunohistochemistry of AFP, VEGF, TF, TUBB1 and MT1G to detect cellular localization. All proteins were found located in either the cytoplasm or cytomembrane of syncytiotrophoblasts and cytotrophoblast cells in the placental villi tissues obtained from control group. Scale bar, $10 \mu \mathrm{m}$. AFP, $\alpha$-fetoprotein; VEGF, vascular endothelial growth factor; TF, transferrin; TUBB1, tubulin $\beta 1$ class VI; MT1G, metallothionein $1 \mathrm{G}$; IVF-ET, in vitro fertilization and embryo transfer.

KEGG pathway and network analysis. The KEGG pathway analysis of differentially expressed genes using KOBAS revealed that the observed genes participated in $>25$ statistically overrepresented pathways. These 10 differentially expressed genes participated in multiple signaling pathways, including EGFR tyrosine kinase inhibitor resistance $\left(n=4\right.$; FDR: $\mathrm{P}=2.78 \times 10^{-8}$; Fig. 5A), hypoxia-inducible factor-1 signaling pathway $(n=4$; FDR $\left.\mathrm{P}=6.92 \times 10^{-8}\right)$, focal adhesion $\left(\mathrm{n}=4\right.$; FDR $\left.\mathrm{P}=9.60 \times 10^{-7}\right)$, microRNAs in cancer $\left(\mathrm{n}=4\right.$; FDR $\left.\mathrm{P}=2.89 \times 10^{-6}\right)$ and PI3K-Akt signaling pathway $\left(\mathrm{n}=4\right.$; FDR $\mathrm{P}=7.05 \times 10^{-6}$; Table III). The 10 differentially expressed genes were also mapped using STRING online software (Fig. 5B). A network was built based on evidence from experimental interactions and databases. A total of 5 interactions between proteins encoded by differentially expressed genes were observed in STRING (Fig. 5B). Bioinformatics analyses of the data suggested that various molecular and cellular functions were affected, and show their link to placental development and functions in the first trimester.

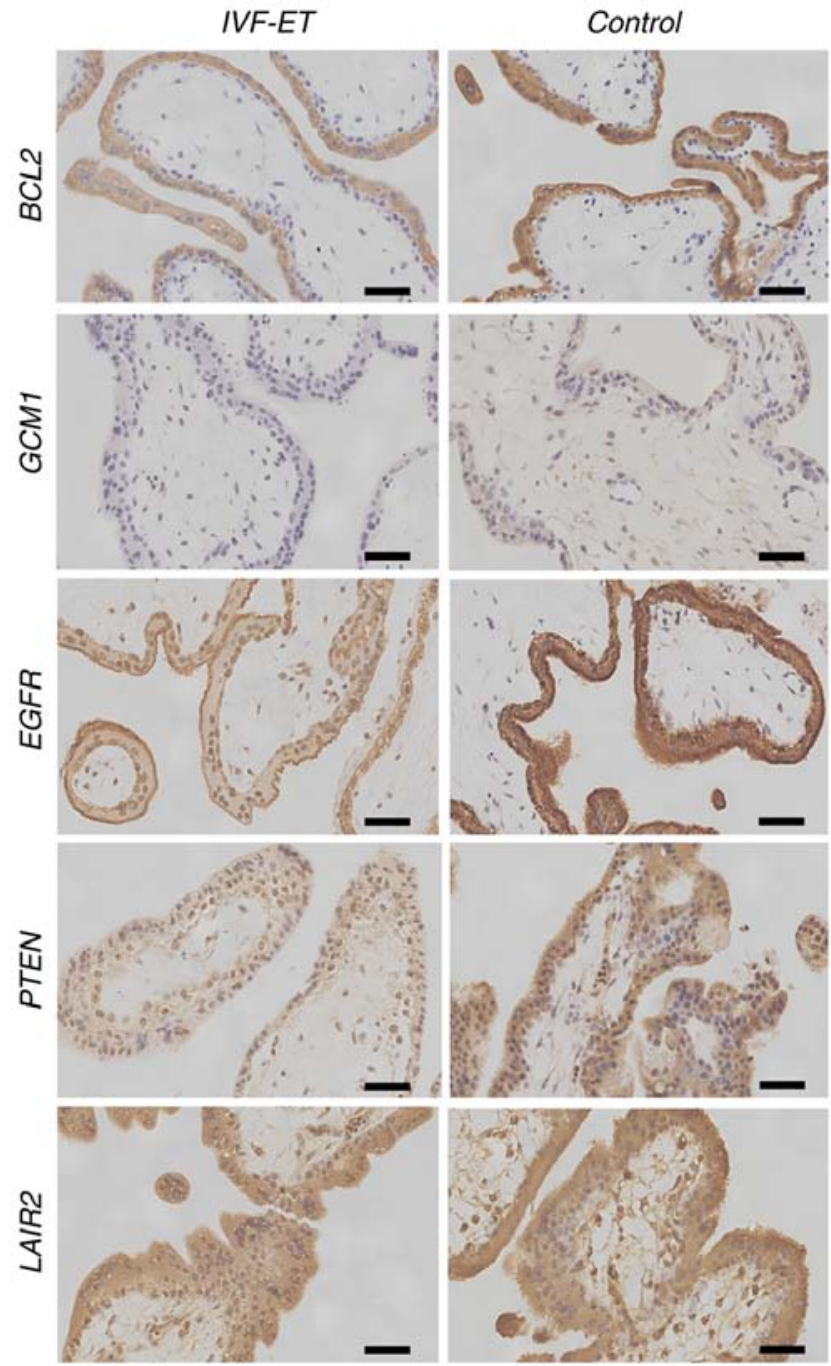

Figure 3. Immunohistochemistry of BCL2, GCM1, EGFR, PTEN and LAIR2 to detect cellular localization. All proteins were located in either the cytoplasm or cytomembrane of syncytiotrophoblasts and cytotrophoblast cells in placental villi tissues obtained from the control group. Scale bar, $10 \mu \mathrm{m}$. GCM1, glial cells missing transcription factor 1; EGFR, epidermal growth factor receptor; LAIR2, leukocyte associated immunoglobulin like receptor 2; IVF-ET, in vitro fertilization and embryo transfer.

\section{Discussion}

The placenta in early pregnancy performs important functions, such as adhesion, differentiation, immune tolerance, invasion, angiogenesis, barrier, nutrition and spiral artery remodeling (30). There has been previous literature on the development and function of the placenta; especially the development of gene chips, making it possible to detect early, middle and late placental genes $(31,32)$. As the changes in placental function are related to pregnancy complications (31), the current research hotspot in the field of obstetrics is to find the early pathological changes of the placenta as fast as possible, and develop early diagnosis and prevention methods. At the same time, it has been found that placental function is closely related to the placental origins of adulthood chronic disease, including metabolic, immune and cardiovascular diseases (33). Therefore, the existing literature and research concluded that the early, middle and late stages of placental development 
Table III. Analysis of differentially expressed genes by KEGG signaling pathway.

\begin{tabular}{|c|c|c|c|}
\hline Term & Input number & P-value & Input \\
\hline $\begin{array}{l}\text { EGFR tyrosine kinase inhibitor } \\
\text { resistance }\end{array}$ & 4 & $2.78 \times 10^{-8}$ & $\begin{array}{l}\text { ENSG00000146648IENSG00000112715|ENSG0000017 } \\
\text { 1791IENSG00000171862 }\end{array}$ \\
\hline HIF-1 signaling pathway & 4 & $6.92 \times 10^{-8}$ & $\begin{array}{l}\text { ENSG00000146648IENSG00000112715|ENSG0000017 } \\
1791 \text { IENSG00000091513 }\end{array}$ \\
\hline Focal adhesion & 4 & $9.60 \times 10^{-7}$ & $\begin{array}{l}\text { ENSG00000146648IENSG00000112715IENSG0000017 } \\
1791 \text { IENSG00000171862 }\end{array}$ \\
\hline MicroRNAs in cancer & 4 & $2.89 \times 10^{-6}$ & $\begin{array}{l}\text { ENSG00000146648IENSG00000112715IENSG0000017 } \\
\text { 1791IENSG00000171862 }\end{array}$ \\
\hline Prostate cancer & 3 & $5.98 \times 10^{-6}$ & $\begin{array}{l}\text { ENSG00000146648IENSG00000171791IENSG0000017 } \\
1862\end{array}$ \\
\hline PI3K-Akt signaling pathway & 4 & $7.05 \times 10^{-6}$ & $\begin{array}{l}\text { ENSG00000146648IENSG00000112715|ENSG0000017 } \\
\text { 1791IENSG00000171862 }\end{array}$ \\
\hline Pathways in cancer & 4 & $1.27 \times 10^{-5}$ & $\begin{array}{l}\text { ENSG00000146648IENSG00000112715IENSG0000017 } \\
\text { 1791IENSG00000171862 }\end{array}$ \\
\hline Bladder cancer & 2 & $1.31 \times 10^{-4}$ & ENSG00000146648|ENSG00000112715 \\
\hline Mineral absorption & 2 & $2.12 \times 10^{-4}$ & ENSG00000091513|ENSG00000125144 \\
\hline Endometrial cancer & 2 & $2.23 \times 10^{-4}$ & ENSG00000146648IENSG00000171862 \\
\hline Glioma & 2 & $3.32 \times 10^{-4}$ & ENSG00000146648IENSG00000171862 \\
\hline Pancreatic cancer & 2 & $3.42 \times 10^{-4}$ & ENSG00000146648IENSG00000112715 \\
\hline Central carbon metabolism in cancer & 2 & $3.53 \times 10^{-4}$ & ENSG00000146648IENSG00000171862 \\
\hline Melanoma & 2 & $3.92 \times 10^{-4}$ & ENSG00000146648IENSG00000171862 \\
\hline Gap junction & 2 & $5.61 \times 10^{-4}$ & ENSG00000146648IENSG00000101162 \\
\hline Small cell lung cancer & 2 & $5.62 \times 10^{-4}$ & ENSG00000171791|ENSG00000171862 \\
\hline Endocrine resistance & 2 & $7.13 \times 10^{-4}$ & ENSG00000146648IENSG00000171791 \\
\hline $\begin{array}{l}\text { AGE-RAGE signaling pathway in } \\
\text { diabetic complications }\end{array}$ & 2 & $7.63 \times 10^{-4}$ & ENSG00000112715|ENSG00000171791 \\
\hline Sphingolipid signaling pathway & 2 & $1.08 \times 10^{-4}$ & ENSG00000171791|ENSG00000171862 \\
\hline FoxO signaling pathway & 2 & $1.29 \times 10^{-4}$ & ENSG00000146648IENSG00000171862 \\
\hline Hepatitis B & 2 & $1.55 \times 10^{-4}$ & ENSG00000171791IENSG00000171862 \\
\hline Proteoglycans in cancer & 2 & $3.12 \times 10^{-4}$ & ENSG00000146648IENSG00000112715 \\
\hline Rap1 signaling pathway & 2 & $3.23 \times 10^{-4}$ & ENSG00000146648IENSG00000112715 \\
\hline Ras signaling pathway & 2 & $3.67 \times 10^{-4}$ & ENSG00000146648IENSG00000112715 \\
\hline Cytokine-cytokine receptor interaction & 2 & $4.79 \times 10^{-4}$ & ENSG00000146648IENSG00000112715 \\
\hline
\end{tabular}

EGFR, epidermal growth factor receptor; HIF-1, hypoxia-inducible factor 1; AGE, advanced glycation endproducts; RAGE, receptor for AGE; FoxO, forkhead box O; Rap1, Ras-related protein 1.

exhibit distinct differences in physiological functions and gene expression, and understanding the effects of pathogenic factors on early placental development, function and gene expression contributes to early diagnosis and medical intervention (34). A growing body of evidence supports the hypothesis that various adverse pregnancy outcomes observed after ART originate from suboptimal placentation caused by abnormal trophoblast function $(2,3)$. In humans, after adjusting for several confounding factors, the risk of spontaneous abortion is higher in ART cohorts than for spontaneous pregnancies (35). Notably, human studies have reported an increased risk of gestational hypertension, preeclampsia, placenta previa and placental abruption in IVF-ET groups $(36,37)$. The placental phenotype is responsive to nutritional conditions. When fetal nutrient availability is compromised, it adapts to maximize the nutrient transfer capacity (38). These compensatory mechanisms may start from the blastocyst stage, within extra-embryonic lineages (39-41). Thus, the aim of the present study was to determine whether there was evidence of functional placental pathology in the first 6-7 weeks of pregnancy after IVF-ET by detecting the expression of candidate genes related to trophoblastic functions.

In the present study, a number of important factors associated with trophoblast cell invasion and placenta formation were selected, and their mRNA and protein expression levels were compared between the IVF-ET group and in those that conceived naturally. The RT-qPCR data revealed that the mRNA expression of AFP, VEGF and TF was upregulated, and TUBB1, MT1G, BCL2, GCM1, EGFR, PTEN and LAIR2 were downregulated in placentas that had undergone IVF-ET 

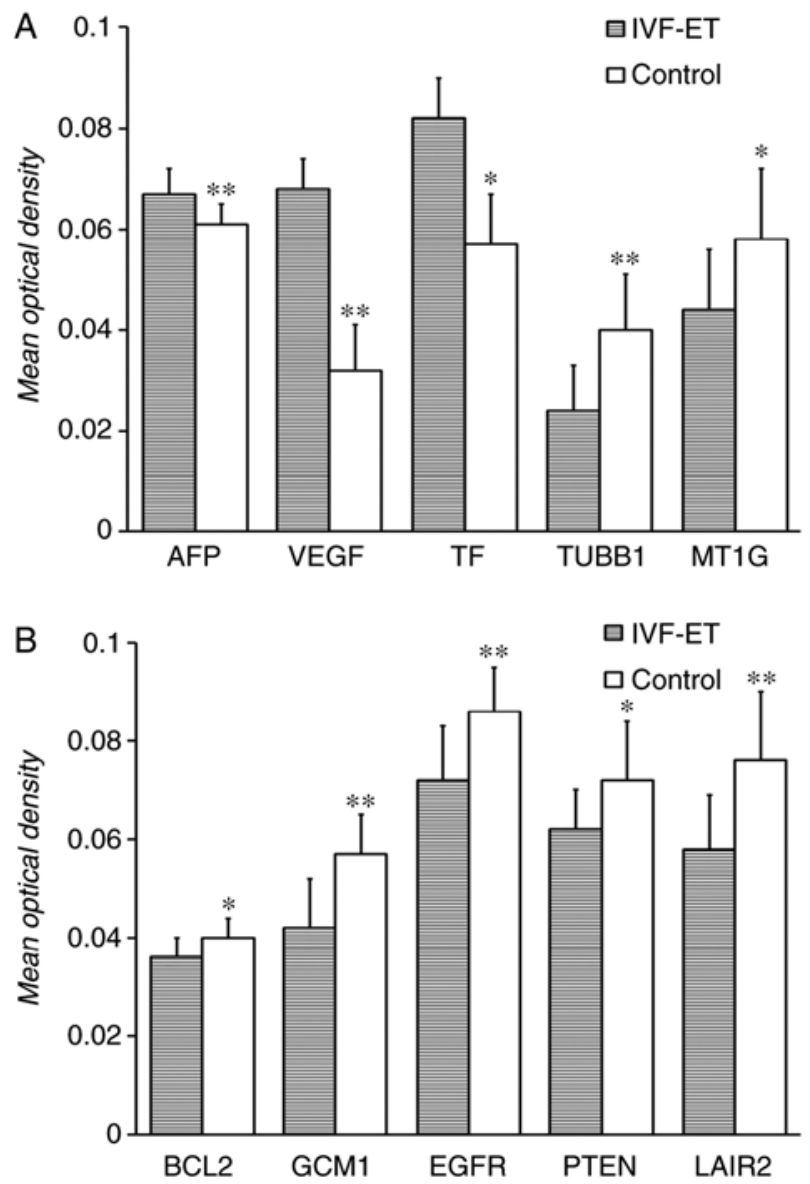

Figure 4. Mean optical density of the positive expression of the selected genes in the two groups. (A) Mean optical density of AFP, VEGF, TF, TUBB1 and MT1G in the placental villus derived from IVF-ET and control group. (B) Mean optical density of BCL2, GCM1, EGFR, PTEN and LAIR2 in the placental villus derived from IVF-ET and control group. $\mathrm{P}<0.05,{ }^{* *} \mathrm{P}<0.01$. IVF-ET, in vitro fertilization and embryo transfer; AFP, $\alpha$-fetoprotein; VEGF, vascular endothelial growth factor; TF, transferrin; TUBB1, tubulin $\beta 1$ class VI; MT1G, metallothionein 1G; GCM1, glial cells missing transcription factor 1; EGFR, epidermal growth factor receptor; LAIR2, leukocyte associated immunoglobulin like receptor 2 .

treatment, when compared with placentas from natural pregnancies. To identify differentially expressed gene products in the human placenta, these candidate factors were selected for IHC analysis, and the results were consistent with those of RT-qPCR. A number of studies have previously examined and identified altered gene expression in placental tissues after IVF-ET treatment (39-41). One study investigated global gene expression in three term placentas from IVF-ET pregnancies compared with 3 placentas from spontaneous pregnancies; they reported 18 differentially expressed genes, and classified them according to their role in biological processes associated with the immune response, transmembrane transport, metabolism, oxidative stress and cell differentiation (42). Furthermore, a previous study on the placental transcriptome after IVF-ET in animals also revealed comparable results (43). The present study used embryo villi in the first trimester and found a variety of genetic changes in trophoblastic function. These results suggested that early placental tissues may undergo extensive genetic and functional changes. Previous animal experimental research supports the hypothesis of the present study (44-46).
It was previously reported that a smaller quantity of trophectoderm cells developed in mouse blastocysts from in vitro culture than in naturally conceived blastocysts $(47,48)$. With regard to in vitro results, placentas were found to be smaller and lighter than control placentas at early gestation, and heavier at late gestation in IVF-ET cases (49). This supports the hypothesis that initial environmental disturbances could trigger placental adaptive responses during pregnancy. Therefore, studying changes in early placental gene expression could be useful in demonstrating the effects of IVF-ET on placental development and function, as well as placenta-derived diseases.

The present study demonstrated that mRNA and protein expression of AFP, VEGF and TF was upregulated in placentas after IVF-ET treatment compared with placentas from natural pregnancies. Under normal circumstances, the expression of AFP in trophoblast cells is weak, and it is mainly located in discontinuous regions at junctions between two villi (50). AFP is derived from trophoblast cells at the maternal-fetal interface in early pregnancy; it is important in regulating angiogenesis, cell growth, inflammatory responses and immune tolerance, as well as participating in important physiological events in the first 3 months of pregnancy $(51,52)$. The main role of AFP is to facilitate the development of the placenta, and the compensatory mechanism is only initiated when blood vessels have developed abnormally. AFP is strongly expressed by villous trophoblastic cells in anembryonic pregnancy compared with the normal group (53). The present study showed that the expression of AFP in the villous tissue of the IVF-ET group was higher than in the control group. This suggested that the upregulation of AFP in the IVF-ET group may indicate a delay of embryo/placenta development rather than disruption of the placenta. This may support our hypothesis that, after IVF-ET, the vascular development of trophoblasts declines, and so there is a compensatory upregulation of AFP in order to ensure normal vascular development in the placenta during the second and third trimesters, as well as to maintain the normal function of the placenta, and protect the exchange of substances and nutrients between the mother's womb and the fetus. A similar mechanism is also hypothesized to occur in regard to VEGF and TF. VEGF improves angiogenesis and ensures normal vascular development in IVF-ET placentas in the first trimester (54). TF is a glycoprotein produced by placental cells that is important in respiration and oxygen transport; therefore, it is required for the effective transport of iron ions throughout the placenta and fetus (55). Abnormal expression of AFP, VEGF and TF early in placental development doubles the risk of preterm delivery, while in the fetus it may contribute to the development of cardiovascular disease in adulthood (56). Thus showing how important these factors are during pregnancy.

In the present study, the mRNA and proteomic expression of TUBB1, MT1G, BCL2, GCM1, EGFR, PTEN and LAIR2 were downregulated in the placentas that had undergone IVF-ET treatment when compared with the control. TUBB1 is a major component of microtubules, which are important cellular matrix structures that are essential for processes such as mitosis, intracellular transportation, cell motility and stability (57). The maintenance and morphology of an integral vascular system is highly reliant on an intact endothelial cytoskeleton (58). It has been hypothesized that impairment of maternal spiral artery remodeling and fetal villi circulation is a leading cause of 


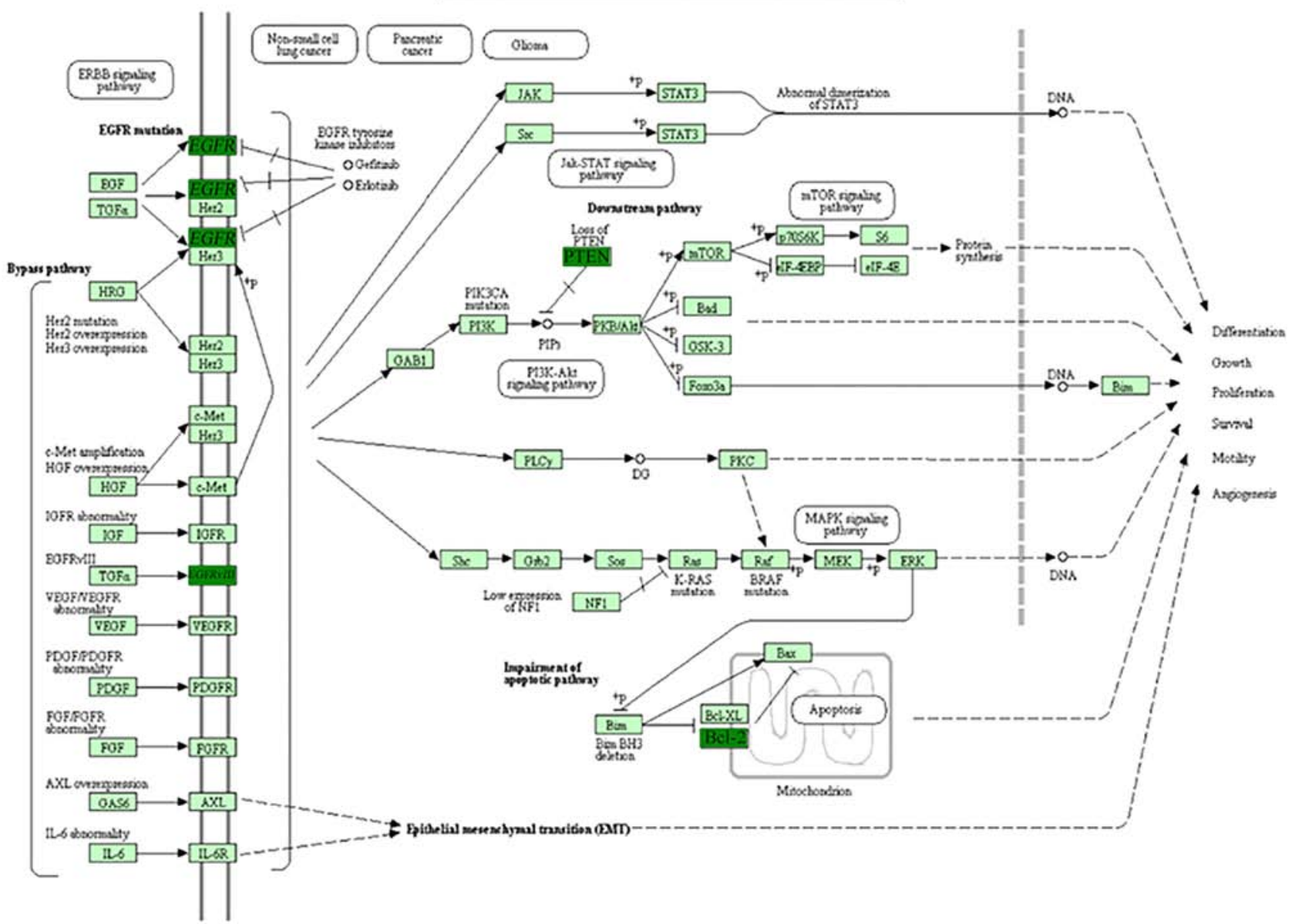

B

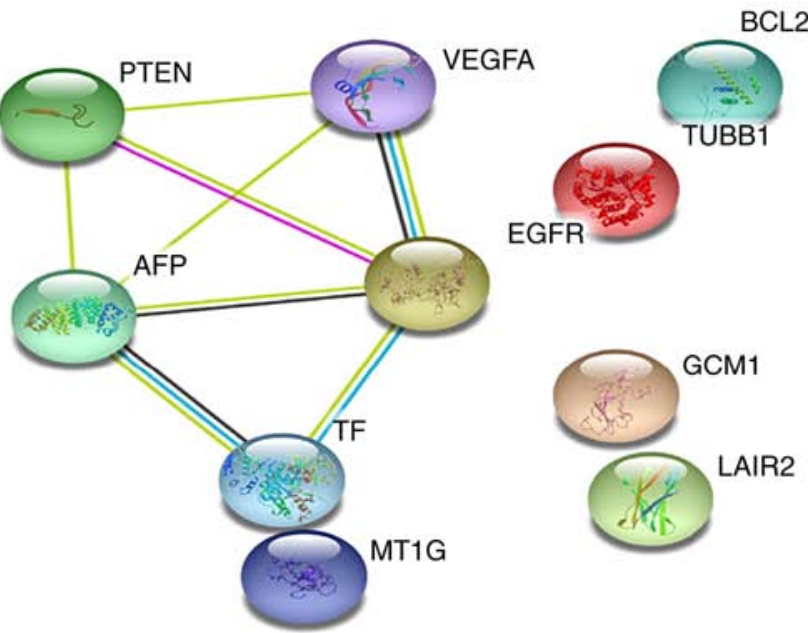

Figure 5. Schematic representation and interaction network of differentially expressed genes in the placenta affected by IVF-ET in the first trimester. (A) Schematic representation showing a number of the differentially expressed genes in the placenta affected by IVF-ET. Dark green represents downregulation; light green represents no significant change. (B) Gene interaction networks of differentially expressed genes in the placenta affected by IVF-ET. All 10 differentially expressed genes were used as input for Search Tool for the Retrieval of Interacting Genes analysis and a network was built. Differentially expressed genes based on high confidence are shown. IVF-ET, in vitro fertilization and embryo transfer; AFP, $\alpha$-fetoprotein; VEGF, vascular endothelial growth factor; TF, transferrin; TUBB1, tubulin $\beta 1$ class VI; MT1G, metallothionein 1G; GCM1, glial cells missing transcription factor 1; EGFR, epidermal growth factor receptor; LAIR2, leukocyte associated immunoglobulin like receptor 2.

preeclampsia (59). MT1G expression in the placenta is important to the structural integrity and function of the placenta (60). Although it does not ameliorate the oxidative stress-induced perturbation of a number of trophoblastic functions, MT1G expression is critical for protecting these similar cells against severe oxidative stress-induced apoptosis (61). BCL2 is considered to be an antiapoptotic factor that is responsible for inhibiting apoptosis in the placenta (62). Apoptosis plays a central role in placental development, homeostasis and immune defense in the placenta, and it is strictly controlled in part by 
members of the BCL2 family (63). Previous independent studies have reported an association between reduced levels of BCL2 and the incidence of premature ruptures in the membranes and the pathogenesis of preterm birth $(64,65)$. GCM1 is a key transcription factor in placental development, and is critical for trophoblastic fusion, placental vasculogenic and maternal vascular remodeling (66). Decreased expression of GCM1, as well as its target genes, has been observed in preeclampsia and trophoblast cells under hypoxia, therefore indicating that GCM1 activity may contribute to the pathogenesis of preeclampsia (67). The binding of EGF and EGFR on trophoblast cells has been shown to stimulate intracellular tyrosine kinase activity and trigger phosphorylation reactions, thereby increasing the nutritional intake of villi, promoting the proliferation and differentiation of the placenta, promoting trophoblastic cell survival and increasing the secretion of placenta (68). A previous study showed that the expression of EGFR was significantly lower in a group of preeclampsia and intrauterine growth retardation cases than in placentas from normal pregnancies (69). PTEN was originally identified as a tumor suppressor and upregulation of PTEN has been shown to increase cell apoptosis (70). In preeclampsia cases, it has been reported that PTEN expression is increased in the placenta, which also leads to increased apoptosis, as well as impaired migration and invasion abilities of trophoblastic cells (71). In the present study, the expression of PTEN in IVF-ET samples was significantly lower than in the control group, which could indicate that PTEN is involved in the adaptive response to placental disturbance. LAIR2 may function to maintain the activation of decidual leukocytes, particularly NK cells at sites of trophoblast invasion (72). Decreased LAIR2 expression may decrease the decidual tolerance of trophoblasts and then result in shallow invasion, fostering the development of preeclampsia and other complications potentially associated with abnormal trophoblast invasion, such as fetal growth restriction and preterm birth (73).

The KEGG pathway analysis of differentially expressed genes revealed $>25$ pathways that were disrupted in the first trimester placenta derived from IVF-ET. Taking the EGFR tyrosine kinase inhibitor resistance-signaling pathway in Fig. 5A as an example, differentially expressed genes and protein molecules interfere with the differentiation, growth, survival and angiogenesis of placental trophoblast cells. Further analysis showed that these pathways are widely involved in key events of early placental development and function, and previous research has shown that disruption of these pathways can lead to adverse outcomes (68). All ten genes were used as input for STRING analysis and a network was built based on high confidence evidence from experimental protein-protein interactions. Parallel approaches using STRING analysis resulted in a total of five interactions between proteins encoded by differentially expressed genes. The present results suggested that IVF-ET treatment and associated processes may interfere with placental formation and function, resulting in placenta-related adverse pregnancy outcomes. However, in the majority of cases, pregnancies achieved via IVF-ET are able to continue without obvious immediate adverse outcomes. This supports the hypothesis that initial defective trophoblast functions could trigger placental adaptive responses during pregnancy. The present study showed that IVF-ET results in suboptimal placental conditions in the first trimester but counterbalancing mechanisms also occurred. The same phenomenon was previously verified in animal experiments. During early pregnancy in mice, IVF-ET placentas and embryos were smaller than those in the naturally conceived group (74). At a later stage, trophoblast cell proliferation was greater in IVF-ET placentas than in the control, in both the labyrinth and spongiotrophoblast layer (75). By birth, IVF-ET placentas were found to be heavier than the control group (76). Likewise, placentas in humans following IVF-ET were overrepresented in the highest quartile of weight, and the placenta weight/birth weight ratio was frequently higher even after adjusting for potential confounding factors (77). A larger placenta is not necessarily synonymous with a higher efficiency in oxygen and nutrient transfer. In response to certain stress factors that modify the early environment of IVF-ET, it is hypothesized that the placenta could amplify these compensatory mechanisms up to a certain point. In the present results, these modified genes and proteins after IVF-ET could have consequences in infancy and adulthood, particularly in relation to metabolic and cardiovascular conditions. In addition, the size and shape of the placenta have been previously associated with life expectancy and risk for coronary heart disease (78). Notably, the available data on the long-term follow-up of IVF-ET children has revealed cardiovascular and metabolic risk factors (79).

A limitation of the present study was the small number of samples investigated in each group. These samples were selected from a cohort of 40 samples collected prospectively for this work. Although the sample size was small, only significant levels of variance in gene and protein expression levels were reported. These data allow future work to be directed towards altered placental formation and function, resulting in placenta-related adverse pregnancy outcomes in IVF-ET cases. Another limitation of the present study is the small number of genes and proteins. Due to the limited number of specimens, this study also lacked experiments to validate the RT-qPCR and IHC, and did not verify the function of candidate genes in cell lines. Additional studies are needed to address these limitations. Further work is needed to determine the biological plausibility of the variations in gene expression, although if results of the present study are consistent across future studies and translate to protein expression in maternal serum, they may still be valuable in predicting abnormal outcomes in the later stages of pregnancy.

The present study indicated the differential gene and protein expression observed between placentas after IVF-ET and those from naturally conceived cases. In the majority of cases, efficient compensatory mechanisms ensure normal fetal growth up to term. When compensation mechanisms are unbalanced, pathological features such as miscarriages, low birth weight or preeclampsia can occur. However, whether this compensation could be a risk factor for certain diseases later in life remains to be determined. The present results will enable researchers to focus on a small number of key genes and proteins that require further investigation. Future studies with a larger sample size focusing on additional molecular mechanisms and proteins may lead to the development of molecular tests to predict adverse outcomes in the first trimester. Understanding the impact on the placenta triggered by IVF-ET will increase the safety of future IVF-ET protocols. 


\section{Acknowledgements}

The authors gratefully acknowledge CapitalBio Corporation for conducting the RNA extractions and RT-qPCR.

\section{Funding}

The present study was supported by the National Nature Science Foundation of China (grant no. 81070493) and Beijing JST Research Funding (grant nos. ZR-201918 and YGQ-201914).

\section{Availability of data and materials}

The datasets used and/or analyzed during the current study are available from the corresponding author on reasonable request.

\section{Authors' contributions}

LZ obtained funding and designed the present study. LS and $\mathrm{LZ}$ carried out the experiments and drafted the manuscript. XZ, JL, RZ, RY and YW acquired, analyzed and interpreted the data. RZ supervised the enrollment of patients, collected clinical data and revised the manuscript for important intellectual content. All authors read and approved the final manuscript.

\section{Ethics approval and consent to participate}

The present study was approved by the Ethics Committees of the Beijing Jishuitan Hospital, Beijing, China, and all participants provided written informed consent.

\section{Patient consent for publication}

Not applicable.

\section{Competing interests}

The authors declare that they have no competing interests.

\section{References}

1. Han Y, Luo H and Zhang Y: Congenital anomalies in infants conceived by infertile women through assisted reproductive technology: A cohort study 2004-2014. Exp Ther Med 16: 3179-3185, 2018.

2. Zhang QF, Chen GY, Liu Y, Huang HJ and Song YF: Relationship between resistin and IL-23 levels in follicular fluid in infertile patients with endometriosis undergoing IVF-ET. Adv Clin Exp Med 26: 1431-1435, 2017.

3. Xiong F, Hu L, Zhang Y and Xiao X: Correlation of hypertensive disorders in pregnancy with procedures of in vitro fertilization and pregnancy outcomes. Exp Ther Med 14: 5405-5410, 2017.

4. Padhee M, Zhang S, Lie S, Wang KC, Botting KJ, McMillen IC, MacLaughlin SM and Morrison JL: The periconceptional environment and cardiovascular disease: Does in vitro embryo culture and transfer influence cardiovascular development and health? Nutrients 7: 1378-1425, 2015.

5. Zhao J, Yan Y, Huang X and Li Y: Do the children born after assisted reproductive technology have an increased risk of birth defects? A systematic review and meta-analysis. J Matern Fetal Neonatal Med 33: 322-333, 2020.

6. Antonelli MC, Pallarés ME, Ceccatelli S and Spulber S: Long-term consequences of prenatal stress and neurotoxicants exposure on neurodevelopment. Prog Neurobiol 155: 21-35, 2017
7. Schagdarsurengin U, Western P, Steger K and Meinhardt A: Developmental origins of male subfertility: Role of infection, inflammation, and environmental factors. Semin Immunopathol 38: 765-781, 2016.

8. Ly L, Chan D and Trasler JM: Developmental windows of susceptibility for epigenetic inheritance through the male germline. Semin Cell Dev Biol 43: 96-105, 2015.

9. Rahat B, Thakur S, Bagga R and Kaur J: Epigenetic regulation of STAT5A and its role as fetal DNA epigenetic marker during placental development and dysfunction. Placenta 44: 46-53, 2016.

10. Panchenko PE, Lemaire M, Fneich S, Voisin S, Jouin M, Junien C and Gabory A: Epigenetics and nutrition: Maternal nutrition impacts on placental development and health of offspring. Biol Aujourdhui 209: 175-187, 2015 (In French).

11. Vincent RN, Gooding LD, Louie K, Chan Wong E and Ma S: Altered DNA methylation and expression of PLAGL1 in cord blood from assisted reproductive technology pregnancies compared with natural conceptions. Fertil Steril 106: 739-748. e3, 2016.

12. de Waal E, Mak W, Calhoun S, Stein P, Ord T, Krapp C, Coutifaris C, Schultz RM and Bartolomei MS: In vitro culture increases the frequency of stochastic epigenetic errors at imprinted genes in placental tissues from mouse concepti produced through assisted reproductive technologies. Biol Reprod 90: 22, 2014.

13. Giritharan G, Delle Piane L, Donjacour A, Esteban FJ, Horcajadas JA, Maltepe E and Rinaudo P: In vitro culture of mouse embryos reduces differential gene expression between inner cell mass and trophectoderm. Reprod Sci 19: 243-252, 2012.

14. Mann MR, Lee SS, Doherty AS, Verona RI, Nolen LD, Schultz RM and Bartolomei MS: Selective loss of imprinting in the placenta following preimplantation development in culture. Development 131: 3727-3735, 2004.

15. Shi X, Yin Z, Ling B, Wang L, Liu C, Ruan X, Zhang W and Chen L: Rho differentially regulates the Hippo pathway by modulating the interaction between Amot and Nf2 in the blastocyst. Development 144: 3957-3967, 2017.

16. Kurowski A, Molotkov A and Soriano P: FGFR1 regulates trophectoderm development and facilitates blastocyst implantation. Dev Biol 446: 94-101, 2019.

17. Ng KYB, Mingels R, Morgan H, Macklon N and Cheong Y: In vivo oxygen, temperature and $\mathrm{pH}$ dynamics in the female reproductive tract and their importance in human conception: A systematic review. Hum Reprod Update 24: 15-34, 2018.

18. Wale PL and Gardner DK: The effects of chemical and physical factors on mammalian embryo culture and their importance for the practice of assisted human reproduction. Hum Reprod Update 22: 2-22, 2016.

19. Chang TA, Bondarenko GI, Gerami-Naini B, Drenzek JG, Durning M, Garthwaite MA, Schmidt JK and Golos TG: Trophoblast differentiation, invasion and hormone secretion in a three-dimensional in vitro implantation model with rhesus monkey embryos. Reprod Biol Endocrinol 16: 24, 2018.

20. Senapati S, Wang F, Ord T, Coutifaris C, Feng R and Mainigi M: Superovulation alters the expression of endometrial genes critical to tissue remodeling and placentation. J Assist Reprod Genet 35: 1799-1808, 2018.

21. Wu L, Li J, Xu HL, Xu B, Tong XH, Kwak-Kim J and Liu YS: IL-7/IL-7R signaling pathway might play a role in recurrent pregnancy losses by increasing inflammatory Th17 cells and decreasing Treg cells. Am J Reprod Immunol 76: 454-464, 2016.

22. Cele SB, Odun-Ayo F, Onyangunga OA, Moodley J and Naicker T: Analysis of hepatocyte growth factor immunostaining in the placenta of HIV-infected normotensive versus preeclamptic pregnant women. Eur J Obstet Gynecol Reprod Biol 227: 60-66, 2018.

23. Balogh A, Toth E, Romero R, Parej K, Csala D, Szenasi NL, Hajdu I, Juhasz K, Kovacs AF, Meiri H, et al: Placental galectins are key players in regulating the maternal adaptive immune response. Front Immunol 19: 1240, 2019.

24. Barrientos G, Pussetto M, Rose M, Staff AC, Blois SM and Toblli JE: Defective trophoblast invasion underlies fetal growth restriction and preeclampsia-like symptoms in the stroke-prone spontaneously hypertensive rat. Mol Hum Reprod 23: 509-519, 2017.

25. He YX, Zhang Y, Yang Q, Wang C and Su G: Selection of suitable reference genes for reverse transcription-quantitative polymerase chain reaction analysis of neuronal cells differentiated from bone mesenchymal stem cells. Mol Med Rep 12: 2291-2300, 2015. 
26. Rao X, Huang $X$, Zhou $Z$ and Lin $X$ : An improvement of the $2^{\wedge}$ (-delta delta CT) method for quantitative real-time polymerase chain reaction data analysis. Biostat Bioinforma Biomath 3: 71-85, 2013.

27. Livak KJ and Schmittgen TD: Analysis of relative gene expression data using real-time quantitative PCR and the 2(-Delta Delta C(T)) method. Methods 25: 402-408, 2001

28. Dheda K, Huggett JF, Bustin SA, Johnson MA, Rook G and Zumla A: Validation of housekeeping genes for normalizing RNA expression in real-time PCR. Biotechniques 37: 112-114, 2004.

29. Kanehisa M, Furumichi M, Tanabe M, Sato Y and Morishima K: KEGG: New perspectives on genomes, pathways, diseases and drugs. Nucleic Acids Res 45: D353-D361, 2017.

30. Choi JH, Jung J, Na KH, Cho KJ, Yoon TK and Kim GJ: Effect of mesenchymal stem cells and extracts derived from the placenta on trophoblast invasion and immune responses. Stem Cells Dev 23: 132-145, 2014.

31. Ujita M, Kondoh E, Chigusa Y, Mogami H, Kawasaki K, Kiyokawa H, Kawamura Y, Takai H, Sato M, Horie A, et al: Impaired Wnt5a signaling in extravillous trophoblasts: Relevance to poor placentation in early gestation and subsequent preeclampsia. Pregnancy Hypertens 13: 225-234, 2018.

32. Uusküla L, Männik J, Rull K, Minajeva A, Kõks S, Vaas $P$, Teesalu P, Reimand J and Laan M: Mid-gestational gene expression profile in placenta and link to pregnancy complications. PLoS One 7: e49248, 2012.

33. Burton GJ, Fowden AL and Thornburg KL: Placental origins of chronic disease. Physiol Rev 96: 1509-1565, 2016.

34. Tarrade A, Panchenko P, Junien C and Gabory A: Placental contribution to nutritional programming of health and diseases: Epigenetics and sexual dimorphism. J Exp Biol 218: 50-58, 2015.

35. Ghaheri A, Rasekhi A, Omani Samani R and Hajizadeh E: modeling in vitro fertilization data considering multiple outcomes observed among Iranian infertile women. Int J Fertil Steril 12: 27-30, 2018

36. Pereira L, Tabata T, Petitt M and Fang-Hoover J: Congenital cytomegalovirus infection undermines early development and functions of the human placenta. Placenta 59 (Suppl 1): S8-S16, 2017.

37. Puscheck EE, Awonuga AO, Yang Y, Jiang Z and Rappolee DA: Molecular biology of the stress response in the early embryo and its stem cells. Adv Exp Med Biol 843: 77-128, 2015.

38. Coan PM, Vaughan OR, Sekita Y, Finn SL, Burton GJ, Constancia M and Fowden AL: Adaptations in placental phenotype support fetal growth during undernutrition of pregnant mice. J Physiol 588: 527-538, 2010.

39. Hiura H, Hattori H, Kobayashi N, Okae H, Chiba H, Miyauchi N, Kitamura A, Kikuchi H, Yoshida H and Arima T: Genome-wide microRNA expression profiling in placentae from frozen-thawed blastocyst transfer. Clin Epigenetics 79: 79, 2017.

40. Litzky JF, Deyssenroth MA, Everson TM, Armstrong DA, Lambertini L, Chen J and Marsit CJ: Placental imprinting variation associated with assisted reproductive technologies and subfertility. Epigenetics 12: 653-661, 2017.

41. Abdel-Hamid AAM, Firgany AEL, Mesbah Y and Soliman MF: Vascular and cellular changes accompany altered expression of angiopoietins in placenta of non-complicated ART pregnancies. Exp Mol Pathol 102: 284-289, 2017.

42. Zhang Y, Cui Y, Zhou Z, Sha J, Li Y and Liu J: Altered global gene expressions of human placentae subjected to assisted reproductive technology treatments. Placenta 31: 251-258, 2010.

43. Armstrong DL, McGowen MR, Weckle A, Pantham P, Caravas J, Agnew D, Benirschke K, Savage-Rumbaugh S, Nevo E, Kim CJ, et al: The core transcriptome of mammalian placentas and the divergence of expression with placental shape. Placenta 57: 71-78, 2017.

44. Faas MM and De Vos P: Innate immune cells in the placental bed in healthy pregnancy and preeclampsia. Placenta 69: 125-133, 2018.

45. de Waal E, Vrooman LA, Fischer E, Ord T, Mainigi MA, Coutifaris C, Schultz RM and Bartolomei MS: The cumulative effect of assisted reproduction procedures on placental development and epigenetic perturbations in a mouse model. Hum Mol Genet 24: 6975-6985, 2015

46. Arnold DR, Gaspar RC, da Rocha CV, Sangalli JR, de Bem THC Corrêa CAP, Penteado JCT, Meirelles FV and Lopes FL: Nuclear transfer alters placental gene expression and associated histone modifications of the placental-specific imprinted gene pleckstrin homology-like domain, family A, member 2 (PHLDA2) in cattle. Reprod Fertil Dev 29: 458-467, 2017.
47. Canel NG, Suvá M, Bevacqua RJ, Arias ME, Felmer R and Salamone DF: Improved embryo development using high cysteamine concentration during IVM and sperm co-culture with COCs previous to ICSI in bovine. Theriogenology 117: 26-33, 2018.

48. Tšuiko O, Catteeuw M, Zamani Esteki M, Destouni A, Bogado Pascottini O, Besenfelder U, Havlicek V, Smits K, Kurg A, Salumets A, et al: Genome stability of bovine in vivo-conceived cleavage-stage embryos is higher compared to in vitro-produced embryos. Hum Reprod 32: 2348-2357, 2017.

49. Grazul-Bilska AT, Johnson ML, Borowicz PP, Baranko L, Redmer DA and Reynolds LP: Placental development during early pregnancy in sheep: Effects of embryo origin on fetal and placental growth and global methylation. Theriogenology 79: 94-102, 2013

50. Fritz R, Kohan-Ghadr HR, Bolnick JM, Bolnick AD, Kilburn BA, Diamond MP, Drewlo S and Armant DR: Noninvasive detection of trophoblast protein signatures linked to early pregnancy loss using trophoblast retrieval and isolation from the cervix (TRIC). Fertil Steril 104: 339-346.e4, 2015.

51. Lafuste P, Robert B, Mondon F, Danan JL, Rossi B, Duc-Goiran P, Mignot TM, Nunez EA, Benassayag $C$ and Ferré F: Alpha-fetoprotein gene expression in early and full-term human trophoblast. Placenta 23: 600-612, 2002.

52. Hughes AE, Sovio U, Gaccioli F, Cook E, Charnock-Jones DS and Smith GCS: The association between first trimester AFP to PAPP-A ratio and placentally-related adverse pregnancy outcome. Placenta 81: 25-31, 2019.

53. Tancrède $\mathrm{S}$, Bujold E, Giguère $\mathrm{Y}$, Renald $\mathrm{MH}$, Girouard $\mathrm{J}$ and Forest JC: Mid-trimester maternal serum AFP and hCG as markers of preterm and term adverse pregnancy outcomes. J Obstet Gynaecol Can 37: 111-116, 2015.

54. Melincovici CS, Bosca AB, Susman S, Mărginean M, Mihu C, Istrate M, Moldovan IM, Roman AL and Mihu CM: Vascular endothelial growth factor (VEGF)-key factor in normal and pathological angiogenesis. Rom J Morphol Embryol 59: 455-467, 2018.

55. Oliveira CM, Rodrigues MN and Miglino MA: Iron transportation across the placenta. An Acad Bras Cienc 84: 1115-1120, 2012.

56. Herr F, Baal N and Zygmunt M: Studies of placental vasculogenesis: A way to understand pregnancy pathology? Z Geburtshilfe Neonatol 213: 96-100, 2009.

57. Matsumura T, Nakamura-Ishizu A, Takaoka K, Maki $\mathrm{H}$, Muddineni SS, Wang CQ, Suzushima H, Kawakita M, Asou N, Matsuoka M, et al: TUBB1 dysfunction in inherited thrombocytopenia causes genome instability. Br J Haematol 185: 888-902, 2019.

58. Gharesi-Fard B, Zolghadri J and Kamali-Sarvestani E: Proteome differences in the first- and third-trimester human placentas. Reprod Sci 22: 462-468, 2015.

59. Huebner H, Knoerr B, Betzler A, Hartner A, Kehl S, Baier F, Wachter DL, Strick R, Beckmann MW, Fahlbusch FB and Ruebner M: Detyrosinated tubulin is decreased in fetal vessels of preeclampsia placentas. Placenta 62: 58-65, 2018.

60. Adebambo OA, Ray PD, Shea D and Fry RC: Toxicological responses of environmental mixtures: Environmental metal mixtures display synergistic induction of metal-responsive and oxidative stress genes in placental cells. Toxicol Appl Pharmacol 289: 534-541, 2015 .

61. Liu C, He X, Hong X, Kang F, Chen S, Wang Q, Chen X, Hu D and Sun Q: Suppression of placental metallothionein 1 and zinc transporter $1 \mathrm{mRNA}$ expressions contributes to fetal heart malformations caused by maternal zinc deficiency. Cardiovasc Toxicol 14: 329-338, 2014.

62. Börzsönyi B, Demendi C, Rigó J Jr, Szentpéteri I, Rab A and Joó JG: The regulation of apoptosis in intrauterine growth restriction: A study of $\mathrm{Bcl}-2$ and Bax gene expression in human placenta. J Matern Fetal Neonatal Med 26: 347-350, 2013.

63. Wierzba W, Tyszko P, Kanecki K and Pinkas J: Proliferation and apoptosis of human placental cells exposed to aromatic hydrocarbons. Ginekol Pol 88: 686-691, 2017.

64. Khera A, Vanderlelie JJ, Holland $O$ and Perkins AV: Overexpression of endogenous anti-oxidants with selenium supplementation protects trophoblast cells from reactive oxygen species-induced apoptosis in a Bcl-2-dependent manner. Biol Trace Elem Res 177: 394-403, 2017.

65. Demendi C, Börzsönyi B, Végh V, Nagy ZB, Rigó J Jr, Pajor A and Joó JG: Gene expression patterns of the Bcl-2 and Bax genes in preterm birth. Acta Obstet Gynecol Scand 91: 1212-1217, 2012. 
66. Bainbridge SA, Minhas A, Whiteley KJ, Qu D, Sled JG, Kingdom JC and Adamson SL: Effects of reduced $\mathrm{Gcm} 1$ expression on trophoblast morphology, fetoplacental vascularity, and pregnancy outcomes in mice. Hypertension 59: 732-739, 2012.

67. Chiu YH, Yang MR, Wang LJ, Chen MH, Chang GD and Chen H: New insights into the regulation of placental growth factor gene expression by the transcription factors GCM1 and DLX3 in human placenta. J Biol Chem 293: 9801-9811, 2018.

68. Kosovic I, Prusac IK, Berkovic A, Marusic J, Mimica M and Tomas SZ: Expression of EGF, EGFR, and proliferation in placentas from pregnancies complicated with preeclampsia. Hypertens Pregnancy 36: 16-20, 2017.

69. Zhao ZM and Jiang J: Lowly expressed EGFR-AS1 promotes the progression of preeclampsia by inhibiting the EGFR-JAK/STAT signaling pathway. Eur Rev Med Pharmacol Sci 22: 6190-6197, 2018.

70. Zhang HJ, Siu MK, Jiang LL, Mak VC, Ngan HY and Cheung AN: Overexpression of the Parkinson disease protein DJ-1 and its regulator PTEN in gestational trophoblastic disease. Int J Gynecol Pathol 29: 468-475, 2010.

71. Xiao J, Tao T, Yin Y, Zhao L, Yang L and Hu L: miR-144 may regulate the proliferation, migration and invasion of trophoblastic cells through targeting PTEN in preeclampsia. Biomed Pharmacother 94: 341-353, 2017

72. Liu J, Zhao H, Zhou F, Huang Y, Chen X, Wang S, Hao J, Xu X, He B and Wang J: Human-specific LAIR2 contributes to the high invasiveness of human extravillous trophoblast cells. Reprod Biol 19: 287-292, 2019.

73. Founds SA, Fallert-Junecko B, Reinhart TA and Parks WT: LAIR2-expressing extravillous trophoblasts associate with maternal spiral arterioles undergoing physiologic conversion. Placenta 34: 248-255, 2013.
74. Weinerman R, Ord T, Bartolomei MS, Coutifaris C and Mainigi M: The superovulated environment, independent of embryo vitrification, results in low birthweight in a mouse model. Biol Reprod 97: 133-142, 2017.

75. Tan K, Zhang Z, Miao K, Yu Y, Sui L, Tian J and An L: Dynamic integrated analysis of DNA methylation and gene expression profiles in in vivo and in vitro fertilized mouse post-implantation extraembryonic and placental tissues. Mol Hum Reprod 22: 485-498, 2016

76. Bloise E, Lin W, Liu X, Simbulan R, Kolahi KS, Petraglia F, Maltepe E, Donjacour A and Rinaudo P: Impaired placental nutrient transport in mice generated by in vitro fertilization. Endocrinology 153: 3457-3467, 2012.

77. Yanaihara A, Hatakeyama S, Ohgi S, Motomura K, Taniguchi R, Hirano A, Takenaka S and Yanaihara T: Difference in the size of the placenta and umbilical cord between women with natural pregnancy and those with IVF pregnancy. J Assist Reprod Genet 35: 431-434, 2018.

78. Kingdom JC, Audette MC, Hobson SR, Windrim RC and Morgen E: A placenta clinic approach to the diagnosis and management of fetal growth restriction. Am J Obstet Gynecol 218 (Suppl 2): S803-S817, 2018.

79. Kawwass JF and Badell ML: Maternal and fetal risk associated with assisted reproductive technology. Obstet Gynecol 132: 763-772, 2018

This work is licensed under a Creative Commons Attribution-NonCommercial-NoDerivatives 4.0 International (CC BY-NC-ND 4.0) License. 